\title{
PERANCANGAN SISTEM INFORMASI PENJUALAN HELM DENGAN BUSINESS MODEL CANVAS (BMC) PADA TOKO NEVAN HELMET BERBASIS E-COMMERCE
}

\author{
Zahrotun Nisa $^{1)}$, Samsinar ${ }^{2)}$ \\ ${ }^{1}$ Sistem Informasi, Fakultas Teknologi Informasi, Universitas Budi Luhur \\ 1,2Jl. Raya Ciledug, Petukangan Utara, Kebayoran Lama, Jakarta Selatan 12260 \\ E-mail : zahrotunatun@gmail.com ${ }^{1)}$, samsinar@budiluhur.ac.id $^{2)}$
}

\begin{abstract}
Abstrak
Teknologi memegang peran sangat penting bagi kehidupan sekarang. Masalah yang sering dihadapi Toko Nevan Helmet adalah stok lama produk tidak laku dipasaran karena kurangnya promosi sehingga pelanggan tidak banyak yang mengetahui ketika ada produk baru. Berdasarkan hal tersebut, maka diperlukannya suatu sistem yang mempermudah Toko Nevan Helmet dalam mempromosikan tokonya. Sistem tersebut diusulkan agar dapat mengatasi permasalahan yang ada pada proses bisnis yang sedang berjalan. Dengan adanya pemanfaatan E-Commerce pada sistem yang baru maka kelemahan-kelemahan yang ada diharapkan dapat diatasi sehingga dapat menghasilkan penyajian informasi yang cepat dan akurat, serta promosi yang cukup kuat dipasaran. Pada saat ini penulis mencoba menganalisa model bisnis dengan menggunakan metode Business Model Canvas (BMC).
\end{abstract}

Kata kunci: E-Commerce, BMC

\section{PENDAHULUAN}

E-commerce atau toko online merupakan salah satu dari sekian banyaknya konsep yang cukup berkembang di dunia internet saat ini. Pengguna sistem ini dapat sangat menguntungkan banyak pikak, baik pihak produsen, penjual maupun konsumen. Konsep online shopping menyediakan banyak sekali kemudahan dan kelebihan dibandingkan dengan konsep belanja yang konvensional [1].

Toko Nevan Helmet ini merupakan saah satu usaha yang bergerak dibidang penjualan, khususnya penjualan helm. Penjualan sendiri artinya yaitu kegiatan yang dilakukan oleh penjual dan pembeli dalam menjual suatu barang atau jasa [2].

Berdasarkan latar belakang dari Toko Nevan Helmet terdapat msalah yang dihadapi, salah satunya yaitu, sulit untuk mencari informasi produk, sehingga pelanggan harus mencari tahu terlebih dahulu produk yang akan dibeli oleh pelanggan dan membutuhkan waktu yang lama untuk mencari informasi tersebut.

Tujuan dari penelitian ini yaitu mempermudah dalam penyajian membuat sistem E-Commerce informasi, maka dari itu menggunakan metode Business Model Canvas sebagai cara agar suatu bisnis tetap berjalan untuk kedepannya nanti, dan hal ini memudahkan para pembisnis dalam berbagai aspek dan bisa diterapkan oleh toko baik skala besar maupun kecil.

Pada penelitian ini penulis merujuk pada penelitian terdahulu dari [3] dengan judul "Perancangan dan Pemanfaatan E-Commerce untuk
Memperluas Pasar Produk Furniture”. Tujuan penelitian menghasilkan sistem E-Commerce untuk furniture melalui integrasi database dan menjalin mitra dengan pelanggan yang dapat dengan mudah dalam memperoleh informasi guna meluaskan area pemasaran dan pasar.

Penelitian terdahulu [4] dengan judul penelitian "Perancangan Dan Implementasi Aplikasi Website TShirt Ewako Screen Printing Berbasiskan ECommerce" Di era globalisasi, banyak perusahaan yang memanfaatkan teknologi sebagai media untuk membuat kegiatan bisnis dan transaksi bisns secara elektronik atau online melalui teknologi internet yang disebut dengan e-commerce. E-commerce adalah suatu cara berbelanja secara online yang memanfaatkan internet dengan medianya berupa website.

Dalam penelitian dari [5] dengan judul "Reengineering website Universitas Ma Chung menggunakan framework the periodic table of SEO success factors”. Dalam upaya memperluas koneksi dan kemitraan dengan berbagai instansi luar, pihak Universitas membangun sebuah website resmi yang digunakan sebagai media informasi internal kepada pihak eksternal. Namun dalam pembuatan sebuah website tidak hanya melihat dari segi tampilan dan informasinyadaja namun keramahan dengan mesin pencari yang kini menjadi salah satu sumber kenjungan terbesar perlu diperhatikan. Search Engine Optimization (SEO) adalah usaha-usaha dalam mengoptimasi website terhadap mesin pencari agar dapat peringkat yang lebih baik SERP. Mesin pencari menggunakan algoritma tertentu dalam 
mengurutkan hasil pencarian yang relevan dengan kata kunci. Dengan mempraktekkan SEO tu berarti menyesuaikan website supaya bersahabat dengan algoritma tersebut sekaligus memudahkan mesin pencari dalam merayapi, mengindeks, dan memahami konten Website. Oleh karena itu, perancangan kembali official website Ma Chung dengan menerapkan factor-faktor penentu keberhasilan dihasil pencarian dibutuhkan sebagai supaya mengoptimalkan kinerja website terhadap mesin pencari.

\section{METODE PENELITIAN}

\subsection{Metodologi Pengumpulan Data}

Dalam sebuah penelitian hal wajib yang harus tersedia adalah data dan informasi, yang nantinya akan diolah menjadi sistem yang dibutuhkan, hal tersebut diperoleh dengan beberapa cara sebagai berikut:

a. Wawancara

Dalam mendapatkan informasi data yang akan diolah diperoleh dengan cara mewawancarai owner dengan memberikan beberapa pertanyaan kepada pemilik toko tersebut untuk mendapatkan beberapa informasi.

b. Observasi

Yang dilakukan saat observasi yaitu dengan terjun langsung melihatat kegiatan jual beli antar pelanggan dan penjual.

c. Teknik Dokumentasi

Merupakan cara pengumpulan data yang telah diberikan oleh pemilik toko, baik berupa nota maupun catatan penjualan pada buku besar.

\subsection{Teknik Analisis Data dan Penggunaan Tools}

a. Analisis Proses Bisnis

Proses Bisnis yang terlah diperoleh saat pengumpulan data kemudian digambarkan menggunakan diagram aktivitas menggunakan tool draw.io, dalam diagram aktivitas tersebut menggambarkan proses bisnis yang saat ini pada Toko Nevan Helmet, Activity Diagram untuk menguraikan bisnis.

b. Analisa Masalah

Analisa masalah merupakan kegiatan mengumpulkan dan meneliti masalah yang ada, pada kegiatan ini terdapat beberapa masalah yang terjadi pada Toko Nevan Helmet, seperti sulitnya mencari pelanggan karena kurangnya promosi, dan sulitnya mencari informasi barang sehingga karyawan toko harus mencari tahu produk yang dimaksud.

c. Analisa Perancangan Sistem

Dalam menganalisa suatu perancangan sistem ini dibuat secara detil berdasarkan dari analisis sistem yang sudah ada, sehingga menghasilkan sistem baru, tools yang digunakan berupa Class Diagram, Rancangan Layar.

\subsection{Metode Analisis}

Metode yang digunakan yaitu Business Model Canvas (BMC) untuk mengidentifikasi model bisnis yang diterapkan oleh Toko Nevan Helmet. Yang dapat membantu membentuk sebuah business plan dalam mengembangakan suatu bisnis [6].

\subsection{Langkah - langkah Penelitian}

Langkah-langkah penelitian yang dilakukan yaitu:

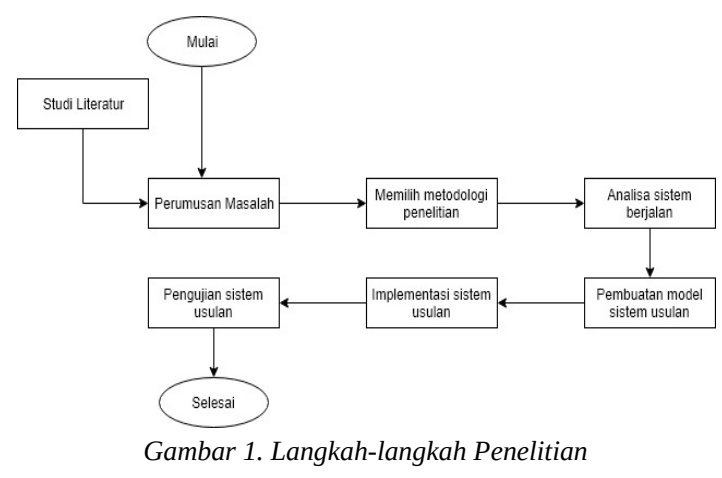

Dibawah ini adalah penjelasan tentang langkah-langkah penelitian diatas:

a. Perumusan Masalah

Merumuskan masalah yang ada pada toko Nevan Helmet merupakan hasil dari kegiatan wawancara dan observasi langsung kepada pemilik toko.

b. Studi Literatur

Tahap ini dilakukan untuk mendapatkan teori yang bersangkutan pada penelitian dan juga teori umum untuk merumuskan masalah. Metode yang dilakukan peneliti yaitu dengan membaca referensi dari artikel yang telah dipublikasikan.

c. Menentukan Metodologi Penelitian

Penulis menentukan metodologi apa yang cocok digunakan dalam menyelesaikan masalah penelitian. Metodologi yang digunakan dalam penelitian ini berupa Business Model Canvas (BMC), bahasa pemrograman menggunakan PHP dengan database MySQL.

d. Analisis Sistem Berjalan

Pada tahap ini, peneliti menganalisa proses bisnis sistem berjalan menggunakan tool Activity diagram.

e. Membuat Sistem Model

Dalam memodelkan sebuah sistem yang diusulkan, penulis melakukan proses identifikasi dengan menggunakan Use Case diagram, Class Diagram.

f. Implementasi Sistem 
Peneliti mengimplementasikan model sistem usulan menggunakan bahasa pemrograman PHP framework dengan database MySQL.

g. Pengujian Sistem

Langkah selanjutnya adalah melakukan pengujian (testing) terhadap sistem usulan yang telah dibuat. Pengujian ini dilakukan setelah implementasi sistem yang bertujuan untuk mengetahui sejauh mana sistem tersebut dapat memenuhi kebutuhan bagi pengguna sistem juga untuk menguji kemampuan sistem dalam mengolah data yang ada

\section{HASIL DAN PEMBAHASAN}

\subsection{Business Model Canvas (BMC)}

BMC merupakan sebuah cara dalam mengenalkan bisnis ke customer dan menjelaskan mengenai model bisnis yang akan dibuat pada toko tersebut. Atau bisa juga untuk menyusun strategi pemasaran dalam bisnis tersebut [6]. Berikut adalah langkah-langkah untuk membuat Business Model Canvas dan deskripsi:

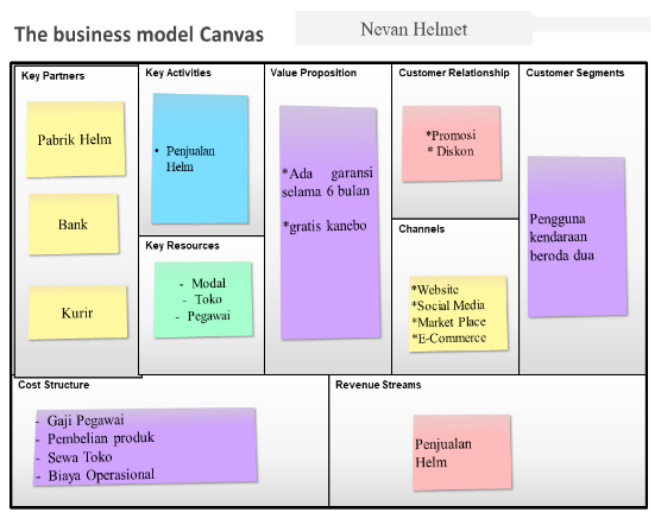

Gambar 2. Business Model Canvas

\section{a. Key Partner}

Nevan Helmet melakukan kerja sama dengan salah satu supplier, Bank dan juga kurir sebagai key partner selama proses penjualan dilakukan.

b. Key Activities

Kegiatan yang menentukan keberhasilan suatu usaha. Cara penjual mendapatkan key activities pada Nevan Helmet adalah dengan mencari distributor yang sudah ternilai standarnya dan berkualitas dengan harga yang mudah dijangkau.

c. Key Resources

Key Resources merupakan komponen yang berisi apa saja yang dibutuhkan agar suatu proses bisnis dapat bekerja.

d. Cost Structure

Cost Structure yaitu biaya yang dikeluarkan dari suatu toko seperti Nevan Helmet ketika mengeksekusi business model nya. Biaya yang dikeluarkan seperti gaji pegawai, pembelian produk helm, menyewa toko dan biaya operasional lainnya.

e. Value Proposition

Toko Nevan Helmet mempunya value proposition yaitu menjual memang barang yang berkualitas dengan harga yang cukup untuk para pelanggan.

f. Channels

Mendiskripsikan bagaimana sebuah produk bisa sampai hingga pelanggan. Toko Nevan Helmet menjual barangnya melalui marketplace seperti Tokopedia, Bukalapak atau bisa juga dibeli secara langsung di Jl. H. Mencong Sudimara Timur Ciledug.

g. Customer Relationship

Customer Relationship yang dijalankan oleh Toko Nevan Helmet yaitu tiap pembelian helm akan mendapatkan sebuah kanebo dan spray untuk membersihkan kaca helm, dan juga mendapatkan garansi selama 1 tahun.

h. Revenue Streams

Merupakan komponen yang berisi bagaimana toko Nevan Helmet mendapatkan penghasilan. Revenue Streams dari Toko tersebut yaitu dari penjualan produk helm.

i. Customer Segments

Toko Nevan Helmet harus menentukan pelanggan yang dituju atau dapat juga disebut segmentasi konsumen. Dari Toko Nevan Helmet memiliki target penjualan produk untuk mulai dari anak- anak, remaja, bapak- bapak dan juga ibu- ibu.

\subsection{Proses Bisnis}

Proses bisnis baru sistem E-Commerce yang dapat dilakukan dimana saja dan bisa kapan saja.

Menurut [7] Activity Diagram yaitu tentang mendeskripsikan aktifitas yang terjadi dari para aktor yang terlibat dalam sistem yang berjalan.

a. Pemesanan

Proses ini dilakukan dengan cara pelanggan login ke Website kemudian pelanggan bisa memilih produk yang ingin dibeli, ketika sudah meng-klik produk yang dipilih sistem akan memunculkan detil produk tersebut, lalu pelanggan mengklik add to cart untuk menginput berapa jumlah produk yang ingin dipesan, setelah itu akan muncul produk yang sudah dipesan, jika pelanggan ingin membeli produk yang berbeda maka pelanggan memilih produk lagi, jika sudah selesai memilih produk maka pelanggan menginput alamat lengkap dan mengklik tombol checkout, kemudian sistem akan menyimpan daftar pesanan lalu admin menerima pesanan, yang terlihat pada Gambar 3: 


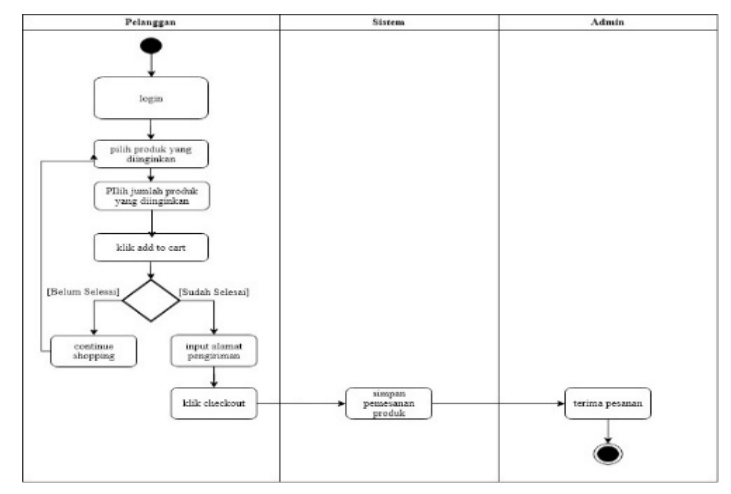

Gambar 3. Activity Diagram Pemesanan

b. Konfirmasi Pembayaran

Pada Gambar 4, Pembayaran dilakukan melalui Bank transfer dengan Nomor Rekening yang tertera pada informasi Website, jika pelanggan selama 2 hari tidak melakukan konfirmasi pembayaran maka pemesanan otomatis akan meng-cancel, tetapi setelah melakukan pembayaran lalu pelanggan login untuk melakukan konfirmasi pembayaran dengan cara mengunggah File Bukti dari pembayaran yang terlah dilakukan, kemudian sistem menyimpan konfirmasi pembayaran lalu admin mengecek menu pembayaran di Admin Dashboard untuk mengubah status pemesanan menjadi proses lalu status pembayaran otomatis menjadi lunas.

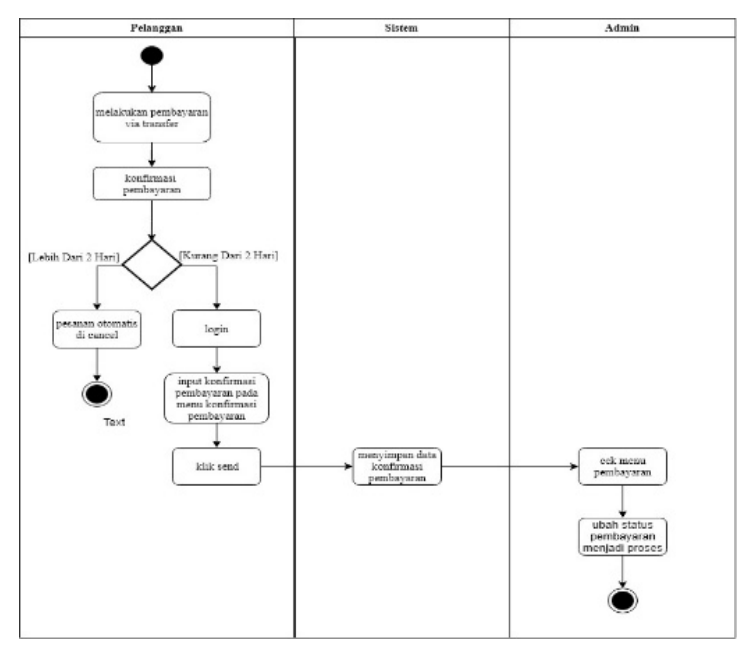

Gambar 4. Activity Diagram Konfirmasi Pembayaran

\section{c. Laporan}

Pada Gambar 5, Admin login halaman Backend Website, lalu membuat laporan pengiriman, laporan pembayaran, laporan pesanan, laporan retur, laporan produk terlaris, admin melihat laporan setiap bulannya.

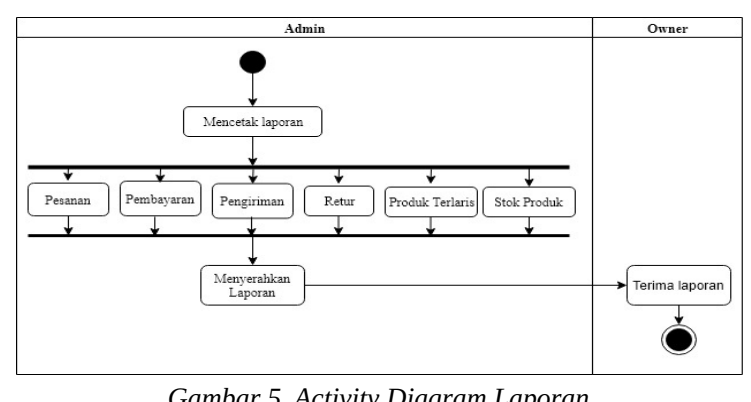

\subsection{Aturan Bisnis}

Adapun aturan bisnis yang terdapat pada toko Nevan Helmet, yaitu:

1. Hanya bisa melakukan tracking di website JNE langsung.

2. Web toko Nevan Helmet tidak menangani proses pembayaran secara online dengan kartu kredit atau jasa pembayaran online lainnya, pembayaran dilakukan secara offline yaitu transfer antar bank dalam melakukan konfirmasi.

3. Kerusakan yang diakibatkan karena pembeli tidak bisa melakukan retur.

4. Ketika melakukan retur, pelanggan harus mengirim barang retur terlebih dahulu, maka barang penggantinya akan dikirim penjual.

5. Harus melakukan konfirmasi pembayaran paling telat 2x24 jam, lebih dari waktu yang ditentukan maka pesanan akan batal.

\subsection{Use Case Diagram}

Use Case adalah kumpulan apa yang akan dilakukan oleh aktor di dalam sistem secara teratur [8].

1. Use Case Diagram Login Pelanggan dan Admin

Pada Gambar 6 merupakan Use Case Diagram Login Pelanggan dan Admin, terdapat dua aktor dalam use case tersebut yaitu pelanggan dan admin.

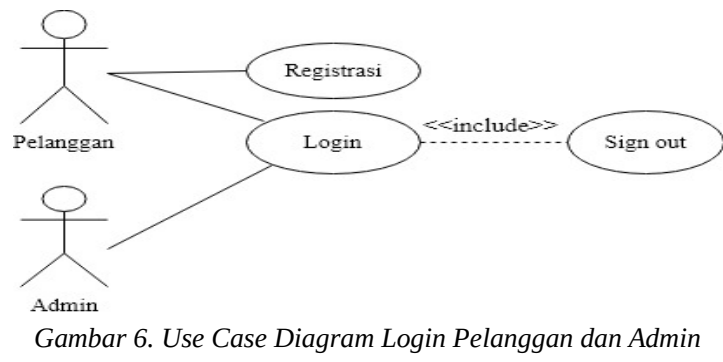

\section{Use Case Diagram Master}

Pada Gambar 7 Use Case Diagram Master yang dilakukan aktor admin untuk menginput data kategori, data produk dan melihat data pelanggan. 


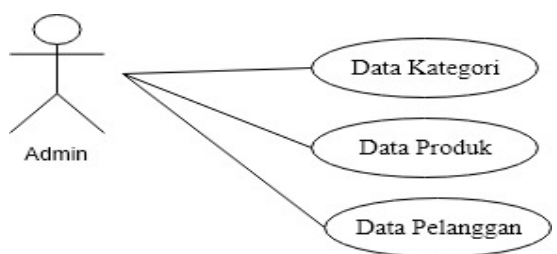

Gambar 7. Use Case Diagram Master

\section{Use Case Diagram Transaksi}

Pada Gambar 8, yang terdapat 2 aktor, yaitu pelanggan dan admin. Pelanggan berperan untuk Input pesanan, Cart, Checkout, Konfirmasi Pembayaran dan Retur. Admin berperan untuk ubah status dan pengiriman.

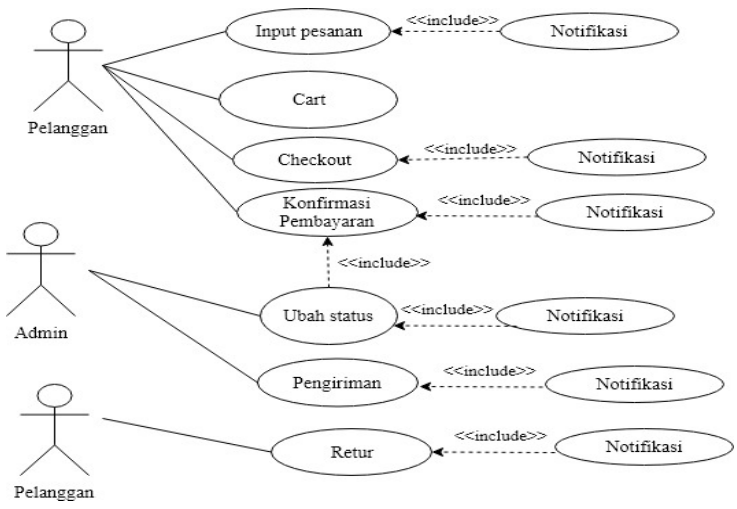

Gambar 8. Use Case Diagram Transaksi

\section{Use Case Diagram Laporan}

Pada Gambar 8 Use Case Diagram Laporan terdapat dua aktor, yaitu Admin dan Owner. Admin dan Owner yang berperan untuk mencetak semua laporan.

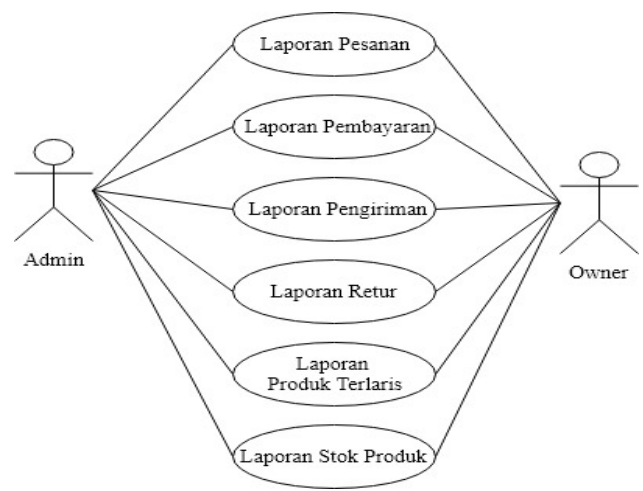

Gambar 9. Use Case Diagram Laporan

\subsection{Tampilan Layar}

Berikut beberapa tampilan layar pada website yang dibuat pada sistem penjualan online Toko Nevan Helmet:

a. Tampilan Layar Detail Produk

Gambar 10 merupakan tampilan layar dari detail produk. Berisi gambra produk, harga produk, nama produk dan add to cart.

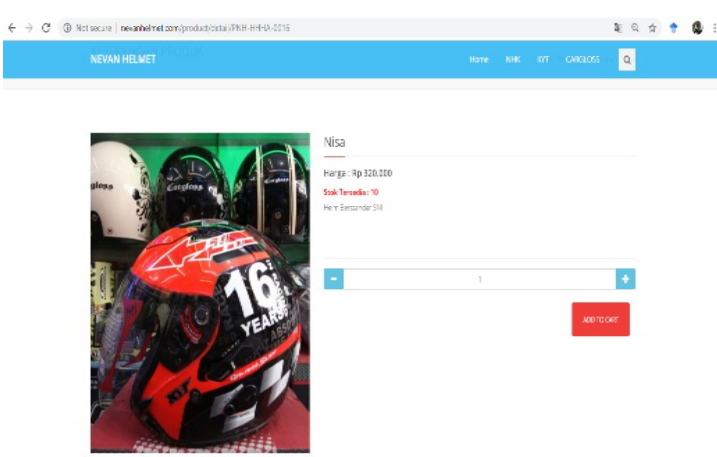

Gambar 10. Tampilan Layar Detail Produk

b. Tampilan Layar Konfirmasi Pembayaran

Gambar 11 merupakan tampilan layar dari konfirmasi pembayaran. Yang berisi untuk menginput data pembayaran.

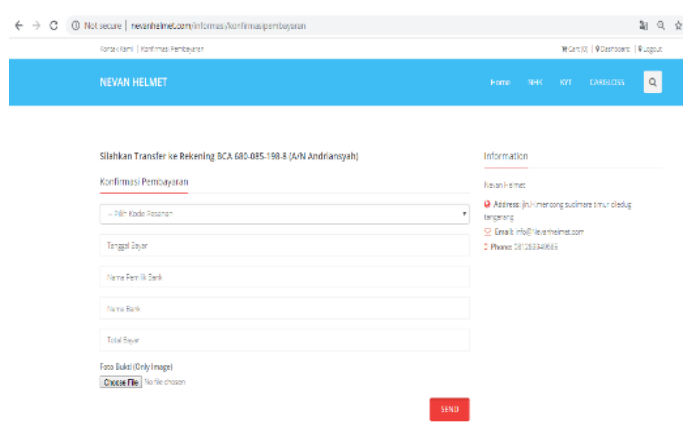

Gambar 11. Tampilan Layar Konfirmasi Pembayaran

c. Tampilan Layar Laporan Pesanan

Gambar 12 merupakan tampilan layar laporan pesanan. Yang berisi Data laporan pesanan.

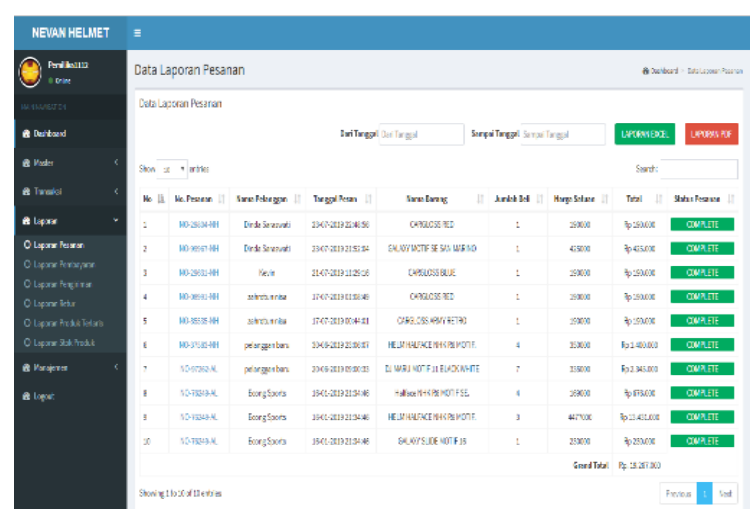

Gambar 12. Tampilan Layar Laporan Pesanan

\section{KESIMPULAN}

Kesimpulan dari penelitian ini yaitu akan mempermudah pelanggan dalam melakukan pembelian produk tanpa harus datang ke toko, 
karena dengan adanya fitur menu kategori produk, maka pencarian informasi produk menjadi lebih mudah. Mempermudah dalam mempromosikan produk secara online, dengan menampilkan produk yang sedang diskon dihalaman utama website. Memudahkan dalam memasarkan stock produk lama yang belum terjual, dengan menampilkan stock produk lama dihalaman awal dengan memberi diskon juga.

\section{DAFTAR PUSTAKA}

[1] Sandblasting Perancangan E-Commerce Batik Pada Batik Banten. Jurnal Ilmiah Sains \& Teknologi, 2(1), 2017, pp. 226-233, ISSN : 1907-1205.

[2] Hartanti Pengaruh Biaya Bahan Baku Dan Biaya Tenaga Kerja Langsung Terhadap Penjualan Bersih Pada Pt Mustika Ratu Tbk.Jurnal Akrab Juara, 3(3), 2016, pp. 10

[3] Sandy, K. Perancangan Dan Pemanfaatan ECommerce Untuk Memperluas Pasar Produk Funiture. Seminar Teknologi Informasi dan Komunikasi SANTIKA 2015, Volume 1, 2018, pp. 225-232, ISSN: 2089-9815.

[4] Ramdhani, M. and Hafidudin Perancangan dan Implementasi Aplikasi Website T-Shirt Ewako Screen Printing Berbasiskan E-Commerce.EProceeding of Applied Science, 1(1), 2015, pp. 781788, ISSN : 2442-5826.

[5] Anul habib, A. and Kurniawan, Y. Reengineering Website Universitas Ma Chung Menggunalan Framework The Periodic Table Of SEO Success Factors. Jurnal Teknologi, Informasi dan Industri, I(1), 2018, pp. 10-20, ISSN : 2615-6474.

[6] Setyorini, R. Analisis Model Bisnis pada Eighteen Nineteen Laundry dengan Pendekatan Business Model Canvas.Journal of Secretary and Business Administration, 1(1), 2018, p. 70.

[7] Yudhanto Rancang Bangun Aplikasi Berbasis Web Perizinan Praktik Tenaga Kesehatan Menggunakan Framework Codeigniter Pada Dinas Kesehatan Kota Metro. Jurnal Tekno Kompak, 11(2), 2017, pp. 5560, ISSN 1412-9663.

[8] Dharmayanti Rancang Bangun Aplikasi Go-Ban Untuk Mencari dan Memanggil Teknisi Tambal Ban Menggunakan Google Maps API., Skripsi: Umsida,15(2), 2018, pp. 2017-2019. 